\title{
The Application of BP Neural Network Model Based on Grey Relational Analysis in the Forecast of Automobile Demand in China's Provinces
}

\author{
LU Zhiping ${ }^{1, a}$, ZHAO Zijuan, ${ }^{2, b, *}$ \\ ${ }^{1}$ Guangxi University of Science and Technology, Liuzhou, Guangxi, China \\ ${ }^{2}$ Guangxi University of Science and Technology, Liuzhou, Guangxi , China \\ a404840561@qq.com,b15676260556@163.com
}

Key words: Grey Relational Analysis; BP neural network; Forecast of Automobile Demand.

\begin{abstract}
Using the principle of grey relational analysis, the influencing factors of automobile demand in various provinces of China are screened, and then the BP neural network model is used to predict the demand for cars in various provinces in China, which greatly improves the prediction accuracy of neural networks and achieves good prediction results.
\end{abstract}

\section{基于灰色关联分析的BP神经网络模型在我国各省汽车需求预测中的应 \\ 用}

\author{
卢志平 $1, \mathrm{a}$,赵紫娟 $2, \mathrm{~b},{ }^{*}$ \\ ${ }^{1}$ 广西科技大学管理学院, 柳州, 广西壮族自治区, 中国 \\ 2 广西科技大学管理学院, 柳州, 广西壮族自治区, 中国 \\ a404840561@qq.com,b15676260556@163.com
}

关键词: 灰色关联分析; $\mathrm{BP}$ 神经网络; 汽车需求预测

中文摘要.利用灰色关联分析原理, 对我国各省汽车需求影响因素进行篮选, 再利用 BP 神经 网络模型对我国各省汽车需求进行预测, 从而大大地提高了神经网络的预测精度, 达到了良 好的预测效果。

\section{1. 引言}

进入 21 世纪以来, 我国汽车行业高速发展, 已成为世界汽车生产及消费大国。研究汽车 市场的未来长期需求不仅可以指导汽车企业制定合理的生产规划, 确保合理的库存, 满足用 户需求，提高汽车产业的经济效益与市场竞争力，而且对政府制定国民经济发展规划、交通 基础设施建设规划和能源环境政策, 以及实施可持续发展战略具有重要的参考价值。因此科 学的需求预测就显得尤为重要。

\section{2. 文献综述}

汽车需求的影响因素问题, 众多学者可谓仁者见仁智者见智。Carlson 借助美国 1965-1975 年汽车数据, 发现最为重要的是可支配收入 ${ }^{[1]}$ 。孙巍, 张馨月借助 Gompertz 模型发现收入的 增加是中国家用汽车需求量增长的主要原因 ${ }^{[2]}$ 。尹小平, 王艳秀发现汽车销量与经济发展速度 密切相关 ${ }^{[3]}$ 。朱英研究得出价格、地区经济状况和政策、营销服务水平、品牌知名度是主要原 因 ${ }^{[4]}$, 而史彦虎和郝彩娟则认为是经济发展水平和全社会固定资产投资 ${ }^{[5]}$ 。陈容分析得出人均 
GDP 和汽车成本是主要因素 ${ }^{[6]}$ 。史四虎综合考虑了人口数量、居民人均消费水平、GDP、石 油消费量和公路里程因素 ${ }^{[7]}$ 。马丽平等运用误差修正模型,发现最大的因素是城市化水平和经 济发展速度。短时间内,汽车价格因素影响甚微。短期用车耗油成本因素始终毫无影响 ${ }^{[8]}$ 。

众多学者对汽车需求的预测也采用了不同的方法。朱广宇等构建了针对整车不确定需求 的组合预测模型, 并利用神经网络进行数据拟合, 并达到了很好的效果 ${ }^{[9]}$ 。朱英研究发现基于 时间序列的预测精度远低于基于影响因素的预测模型 ${ }^{[4]}$ 。施卫海研究发现 BP 神经网络法对非 线性、周期性、大幅度波动的产品具有良好的适应性 ${ }^{[10]}$ 。

神经网络预测法不需要考虑模型的内部结构, 不需要人为地确定因子权重, 只要提供一 定的学习样本，网络通过“自学习”，能够从大量复杂数据中找出输入与输出模式之间的非线 性定量关系, 并且以隐式方式存储在各层神经元之间的连接权矩阵中。相对于传统预测模型, 神经网络模型人工干预少, 建立过程简单, 而且模型的仿真精度高。本文利用灰色关联分析 原理, 对我国各省汽车需求的影响因素进行篮选, 再利用 BP 神经网络模型对我国各省汽车 需求进行预测, 从而大大地提高了 $\mathrm{BP}$ 神经网络的训练精度, 并且达到了良好的预测效果。

\section{3. 理论模型}

\section{1 灰色关联理论}

1982 年，邓聚龙教授提出了灰色系统理论。而灰色关联分析不仅是灰色系统的关键组 成部分, 也是灰色系统预测和决策分析的理论基础 ${ }^{[1-13]}$ 。在系统中, 由于信息的不确定性和 不完整性, 我们很难去区分主要因素和次要因素。只有分清主次, 我们才能更好地去管理以 及控制整个系统。灰色关联分析的目的就是找出系统中的主要因素与次要因素, 其具体计算 步骤如下:

1.根据评价目的确定评价的指标体系，收集评价数据。

2.确定比较数列和参考数列。影响系统行为的数列为比较数列。反映系统行为特征数列 为参考数列。

3.对评价指标数据进行无量纲化处理。本文中采用初值化法处理。

4.逐个计算比较序列与参考序列对应元素的绝对值。

5.求上述求得的绝对值的最小值和最大值。

6. 计算关联系数。本文取 $\rho=0.5$ 。

7.计算关联度。

\subsection{BP神经网络}

1986 年 Rumelhart 等提出了误差反向传播算法, 简称 BP 算法 ${ }^{[14]}$ 。它由输入层、隐含层、 输出层组成。 BP 神经网络算法分成信息正向计算和误差后向传播两个阶段。如果正向传播 输出的误差达不到预期精度, 则沿误差的负梯度方向反复修改各层神经元的权值和阈值, 直 至网络全局误差信号最小。

\section{4. 我国各省汽车需求的灰色关联分析}

\section{1 我国各省汽车需求影响因素的数据来源}

借鉴前人对汽车需求影响因素的研究, 本研究将人均 GDP、原油消耗量、人均消费水平、 公路里程、城市化水平作为汽车需求的影响因素。本文收集了 2010-2016 年我国各省的人均 $\mathrm{GDP}(\mathrm{X} 1)$ 、原油消耗量 $(\mathrm{X} 2)$ 、人均消费水平 (X3)、公路里程 (X4)、城市化水平 (X5)、 汽车需求量 (X6), 汽车需求量用私人汽车拥有量代替。数据均来自于国家统计局、中经网统 计数据库、各省统计局, 由于山西省, 贵州省, 西藏自治区的原油消耗量数据缺失, 因此研 究样本删除了这三个省。 


\section{2 我国各省汽车需求影响因素的灰色关联分析}

将汽车需求量 (X6) 作为参考数列, 把影响汽车需求的因素人均 GDP (X1)、原油消耗 量 (X2)、人均消费水平 (X3)、公路里程 (X4)、城市化水平 (X5) 作为比较数列计算关联 度。用 MATLABR2016a 编程得出各省汽车需求影响因素的灰色关联度如表 1 所示。

表 1 灰色关联度

\begin{tabular}{|c|c|c|c|c|c|c|c|c|c|c|c|}
\hline 地区 & $\mathrm{X} 1$ & $\mathrm{X} 2$ & $\mathrm{X} 3$ & $\mathrm{X} 4$ & $\mathrm{X} 5$ & 地区 & $\mathrm{X} 1$ & $\mathrm{X} 2$ & $\mathrm{X} 3$ & $\mathrm{X} 4$ & $\mathrm{X} 5$ \\
\hline 北京 & 0.3364 & 0.9873 & 0.5871 & 0.6894 & 0.9913 & 河南 & 0.7989 & 0.9974 & 0.9221 & 0.3434 & 0.9954 \\
\hline 天津 & 0.3368 & 0.9714 & 0.6559 & 0.7572 & 0.996 & 湖北 & 0.7456 & 0.9931 & 0.8997 & 0.3452 & 0.9976 \\
\hline 河北 & 0.7087 & 0.9911 & 0.8943 & 0.3418 & 0.9919 & 湖南 & 0.7767 & 0.9961 & 0.9068 & 0.3457 & 0.9973 \\
\hline 内蒙古 & 0.5902 & 0.9991 & 0.8473 & 0.3504 & 0.9972 & 广东 & 0.651 & 0.9667 & 0.8303 & 0.3461 & 0.9907 \\
\hline 辽宁 & 0.52 & 0.9044 & 0.7609 & 0.351 & 0.9941 & 广西 & 0.6715 & 0.9844 & 0.8434 & 0.351 & 0.9963 \\
\hline 吉林 & 0.5419 & 0.985 & 0.8106 & 0.3562 & 0.9961 & 海南 & 0.3421 & 0.9522 & 0.5988 & 0.4186 & 0.9972 \\
\hline 黑龙江 & 0.703 & 0.9777 & 0.8673 & 0.3459 & 0.9972 & 重庆 & 0.6245 & 0.9882 & 0.8248 & 0.3558 & 0.9978 \\
\hline 上海 & 0.338 & 0.9559 & 0.5422 & 0.7899 & 0.9966 & 四川 & 0.8339 & 0.9991 & 0.9296 & 0.3407 & 0.9968 \\
\hline 江苏 & 0.5452 & 0.9712 & 0.794 & 0.362 & 0.9912 & 云南 & 0.8323 & 0.9972 & 0.9184 & 0.343 & 0.9972 \\
\hline 浙江 & 0.4858 & 0.9683 & 0.7269 & 0.3564 & 0.9884 & 陕西 & 0.6836 & 0.979 & 0.875 & 0.3489 & 0.9968 \\
\hline 安徽 & 0.7462 & 0.997 & 0.8861 & 0.3435 & 0.9968 & 甘肃 & 0.7528 & 0.9805 & 0.8817 & 0.3442 & 0.9983 \\
\hline 福建 & 0.4922 & 0.9788 & 0.7606 & 0.3579 & 0.995 & 青海 & 0.5264 & 0.9973 & 0.77 & 0.3571 & 0.9989 \\
\hline 江西 & 0.7241 & 0.996 & 0.876 & 0.3469 & 0.9976 & 宁夏 & 0.339 & 0.9851 & 0.5931 & 0.4063 & 0.9968 \\
\hline 山东 & 0.7078 & 0.955 & 0.8903 & 0.3455 & 0.9923 & 新疆 & 0.7177 & 0.974 & 0.8894 & 0.3449 & 0.9981 \\
\hline
\end{tabular}

一般认为, 关联度 $>=0.8$, 说明关联度很好; $0.6<=$ 关联度 $<0.8$ 时说明关联度较好; 关联度 $<0.5$ 时说明不相关。因此要删除关联度 $<0.5$ 的因素, 同时依据影响因素的种类将样本分为五类， 如表 2 所示。

表 2 样本分类

\begin{tabular}{|c|c|}
\hline 影响因素 & 地区 \\
\hline X2 X4 X5 & 北京 上海 \\
\hline X2 X5 & 海南 宁夏 \\
\hline X2 X3 X4 X5 & 天津 \\
\hline X1 X2 X3 X5 & 河北黑龙江 安徽 江西 山东 河南 湖北 湖南 广东 广西 重庆 \\
& 四川 云南 陕西 甘肃 新疆 \\
\hline X2 X3 X5 & 内蒙古 辽宁 吉林 江苏 浙江 福建 青海 \\
\hline
\end{tabular}

\section{5. 基于灰色关联分析的BP神经网络模型对我国各省汽车需求的预测}

\section{1 基于灰色关联分析的BP神经网络模型的建立}

该神经网路模型一共有 3 层, 依次为输入层、隐含层、输出层。根据表 2 的分类结果, 分别将各分类对应的影响因素指标值作为神经网络的输入, 将汽车需求量作为神经网络的输 出。隐含层的节点数是根据网络学习的收敛速度进行选取。

\section{2 基于该模型数据的训练}

利用该模型对各省汽车需求进行预测。首先为了保证数据是统一数量级, 将各个省的城 市化率乘以 1000, 然后对所有指标数据进行取对数法处理。选取各个分类的 2010-2015 年的 数据作为训练样本, 2016 年作为测试样本, 借助 MATLAB 神经网络工具箱对模型进行拟合。

\section{3 基于该模型数据的检验}

利用上述训练好的模型分别对分类样本进行检验, 各省汽车需求预测结果以及误差如表 3 所示。其中方法 1 指 BP 神经网络算法, 方法 2 指基于灰色关联分析的 BP 神经网络算法。 
表 3 各省汽车需求预测结果

\begin{tabular}{|c|c|c|c|c|c|c|c|c|c|c|c|}
\hline 地区 & 实际数据 & $\begin{array}{c}\text { 方法 } 1 \text { 预测 } \\
\text { 结果 }\end{array}$ & $\begin{array}{c}\text { 方法 } 1 \text { 预 } \\
\text { 测误差 }\end{array}$ & $\begin{array}{c}\text { 方法 } 2 \text { 预测 } \\
\text { 结果 }\end{array}$ & $\begin{array}{c}\text { 方法 } 2 \text { 预测 } \\
\text { 误差 }\end{array}$ & 地区 & $\begin{array}{r}\text { 实际数 } \\
\text { 据 }\end{array}$ & $\begin{array}{c}\text { 方法 } 1 \text { 预测结 } \\
\text { 果 }\end{array}$ & $\begin{array}{c}\text { 方法 } 1 \\
\text { 预测误 } \\
\text { 差 }\end{array}$ & $\begin{array}{c}\text { 方法 } 2 \text { 预测结 } \\
\text { 果 }\end{array}$ & $\begin{array}{c}\text { 方法 } 2 \text { 预 } \\
\text { 测误差 }\end{array}$ \\
\hline 天津 & 234.39 & 233.6684 & -0.0031 & 234.8551 & 0.0020 & 安徽 & 511.45 & 500.3658 & -0.0217 & 504.7299 & $\begin{array}{l}-0.0131 \\
\end{array}$ \\
\hline 北京 & 452.04 & 434.6103 & -0.0386 & 439.3392 & -0.0281 & 江西 & 349.06 & 338.2361 & -0.0310 & 339.8600 & -0.0264 \\
\hline 上海 & 242.66 & 241.9357 & -0.0030 & 242.2580 & -0.0017 & 山东 & 1550.65 & 1498.3042 & -0.0338 & 1527.0667 & -0.0152 \\
\hline 海南 & 82.87 & 81.7900 & -0.0130 & 83.4257 & 0.0067 & 河南 & 992.37 & 934.3294 & -0.0585 & 973.2145 & -0.0193 \\
\hline 宁夏 & 103.63 & 103.3949 & -0.0023 & 103.4897 & -0.0014 & 湖北 & 519.69 & 526.8658 & 0.0138 & 523.3954 & 0.0071 \\
\hline 内蒙古 & 379.95 & 348.4978 & -0.0828 & 390.9309 & 0.0289 & 湖南 & 544.16 & 518.6594 & -0.0469 & 529.5415 & -0.0269 \\
\hline 辽宁 & 553.39 & 558.4702 & 0.0092 & 552.3892 & $\begin{array}{l}-0.0018 \\
\end{array}$ & 广东 & 1485.17 & 1454.6766 & -0.0205 & 1464.3859 & -0.0140 \\
\hline 吉林 & 315 & 310.5990 & -0.0140 & 313.1843 & -0.0058 & 广西 & 375.81 & 358.0534 & -0.0472 & 362.2827 & -0.0360 \\
\hline 江苏 & 1245.83 & 1163.8580 & -0.0658 & 1234.8096 & -0.0088 & 重庆 & 278.64 & 288.0575 & 0.0338 & 279.5117 & 0.0031 \\
\hline 浙江 & 1104.23 & 1110.8082 & 0.0060 & 1108.8082 & 0.0041 & 四川 & 786.03 & 767.6122 & -0.0234 & 770.4370 & -0.0198 \\
\hline 福建 & 435.31 & 447.0952 & 0.0271 & 444.9385 & 0.0221 & 云南 & 498.07 & 486.5519 & -0.0231 & 490.8812 & -0.0144 \\
\hline 青海 & 72.96 & 76.2079 & 0.0445 & 74.1822 & 0.0168 & 陕西 & 440.26 & 434.2839 & -0.0136 & 435.8700 & -0.0100 \\
\hline 河北 & 1143.78 & 1043.9693 & -0.0873 & 1078.6398 & -0.0570 & 甘肃 & 207.41 & 212.3244 & 0.0237 & 210.1693 & 0.0133 \\
\hline 黑龙江 & 344.29 & 350.5097 & 0.0181 & 349.9158 & 0.0163 & 新疆 & 266.39 & 278.5480 & 0.0456 & 276.8854 & 0.0394 \\
\hline
\end{tabular}

从表 3 可得, 方法 1 的平均误差为-0.0146, 方法 2 的平均误差为-0.0050, 从而验证了模 型的有效性。

\section{6. 结论}

从表 3 结果可看出, 基于灰色关联度分析的 BP 神经网络算法, 在拟合精度方面优于传统 的 BP 神经网路算法，从而验证了本算法的有效性和实用性。

\section{致谢}

本文为广西哲学社会科学规划研究课题“互联网+”背景下广西汽车制造业服务化及其服 务转型问题研究” (项目批准号：15DGL004）的阶段性成果之一。

\section{References}

[1] Carlson, Seemingly Unrelated Regression and the Demand for Automobiles of Different Sizes[J]. Journal of Business, 1978, (2): 243-262.

[2] Sun wei,Zhang Xinyue. Calculation of Saturation Point of Domestic Cars in China - Dynamic Panel Estimation Based on Gompertz Model [J]. Consumer economy,2011,27(01):46-49.

[3] Yi Xiaoping,Wang Yanxiu. An Empirical Analysis of the Influencing Factors of China's Automobile Sales [J]. Statistics and Decision,2011(08):98-100.

[4] Zhu Ying. Improved BP Neural Network Prediction Model and Its Application [J]. Journal of Wuhan University of Technology (Transportation Science and Engineering Edition),2012,36(06):1252-1255.

[5] Zhu Yanhu,He Caijuan,Zhu Xianqi. Analysis of Influence Factors of Automobile Market Demand Based on Grey Relational Model [J]. Journal of Shanxi Agricultural University,2012, (2): 155-159.

[6] Chen Rong. Long-term Forecasting Method of Automobile Market Demand Based on Innovative Product Diffusion Theory and Empirical Research [D]. Chongqing University,2012.

[7] Shi Sihu. Demand Forecasting Model Based on Improved Grey System-BP Neural NetworkSupport Vector Machine [D]. Northeastern University,2012.

[8] Ma Liping,Zhang Jianhui. Analysis of Influence Factors of Vehicle Demand Based on Error Correction Model [J]. Technology Management Research,2014,34(07):106-109. 
[9] Zhu Guangyu,Lei Li,Bi Jun,Li Baowen. A Combined Forecasting Model for Uncertain Vehicle Demands [J]. Mathematics Practice and Understanding,2007,(08):27-31.

[10] Shi Weihai. Research on Application of Predictive Model for Automobile Parts Enterprises [D]. Shanghai Jiaotong University,2014.

[11]Yan Zhiyuan,Dai Yusheng. Grey System Prediction and Application [M]. Suzhou: Jiangsu Science and Technology Press, 1989.

[12]Chen Huayou,Zhao Jiabao,Liu Chunlin. The Nature of the Combined Forecasting Model Based on the Degree of Gray Incidence [J]. Journal of Southeast University, 2004,34(1):131 — 134.

[13]Xie Kaigui,He Bin.ect. A New Method of Grey Prediction Model [J]. System Engineering Theory and Practice, 1998,(7):69-75.

[14]Rumelhart D E,Hinton G E,Williams R J.Learning representations by back-propagation error.Nature,1986,323(9):533-536. 